\title{
Editorial
}

\section{Curriculum matters in an extraordinary year}

\author{
Jane Abbiss \\ https://doi.org/10.18296/cm.0045
}

This year, 2020, has been an extraordinary year. It has seen the escalation of COVID-19 to global pandemic status, the Black Lives Matter movement, the Aotearoa New Zealand election in October (delayed by a month due to the COVID-19 pandemic) and the US Presidential election in November. These events highlight a range of issues that are of potential interest to curriculum researchers and scholars and provide fruitful areas for ongoing curriculum research and exploration.

But first a word of thanks. Many of the contributors and supporters of Curriculum Matters are teachers as well as researchers. This year, these teachers have had to respond to a range of challenges, including redesigning teaching and assessment programmes for online learning; guiding and supporting learners with transitions into, during, and out of periods of online and homebased learning; and supporting families and colleagues as everyone has dealt with the pressures and disruptions of the COVID-19 year. I acknowledge every author who submitted a manuscript for consideration for publication, and the contributions of each of the authors who worked through the review process and whose articles are included in this edition of the journal, along with every reviewer who accepted an invitation to review a manuscript and thereby provided support for authors. This year has not been "business as usual" and people have needed to prioritise their time and energy. To all of those who have supported Curriculum Matters this year alongside all of your other responsibilities, thank you.

Turning now to focus on some curriculum matters that were illuminated by the events of 2020, prominent among issues that have emerged are questions relating to learners' access to curriculum in a digital environment, engagement 


\section{Editorial}

with and learning about issues of social justice, and development of critical thinking and critical media literacy. On the matter of access, the closure of centres, schools, and tertiary education institutions for face-to-face teaching during hightened COVID-19 alert levels and move to learning online and via television learning channels revealed that access to the curriculum is not equitable for all learners. While many learners had devices at home and good internet connections, not all families had the level of technology that was needed to support learning from home. Also, family members were required to take on learning support roles for children who were learning from home and these parents, grandparents, siblings, and extended family may have felt more or less confident and supported to take on this role. The issue of access was very obvious in the particular circumstance of a sudden, national shift to online learning, but questions of access are broader than COVID-19. With the movement towards digital and blended learning in a range of educational contexts, it cannot be assumed that all students have equal access to this form of learning and to curricula that are presented in a digital environment. When seeking to move learning online and into a digital space, it is clear that questions need to be asked by educators, policy makers, and administrators about who is and who is not able to access this space and about those whose access is not optimal. The follow-up questions relate to what to do about this and how to support equitable access for learners in digital educational environments so that issues of access to curriculum do not create or exacerbate inequalities.

For people who are interested in curriculum and what is taught and learnt by learners at a range of levels within the educational system, the events of 2020 have highlighted a variety of issues of social (in)justice that could be a focus of teaching and learning. The Black Lives Matter movement has shone a particular light on racism in the US and beyond. In experiencing and observing the movement, educators are moved to ask questions about systemic racism and why this has been invisible or ignored by many, particularly white people who do not suffer racism themselves, and how it is perpetuated through social, political, and economic systems and structures. Also, it invites soul-searching and consideration by educators about their roles and responsibilities in teaching about and addressing issues of racism. During the year and inspired by Black Lives Matter, people in Aotearoa New Zealand marched in solidarity with the movement, and local social 
justice campaigners focused on issues of racism in Aotearoa New Zealand. The issues are close to home. They are also not new issues. Activists and researchers have focused on and highlighted issues of racial and social injustice in Aotearoa New Zealand for decades, including in education. Curriculum-related questions include: What could, and should, those who influence curriculum policy and the curriculum in practice do about this? How do educators ensure that this moment of opportunity to act for social justice through curriculum is not lost?

For anyone who engaged with media sources during the year and with the US election getting intense global media coverage, claims of "fake news" were hard to miss, especially the accusations from President Trump and his supporters during the Presidential election campaign. The issue with "fake news" is not just whether various claims made about media bias may or may not be accurate and whether and how those claiming "fake news" are obfuscating and creating misinformation (although asking questions about the veracity of information is very important), but also how topics get presented through the media and the role of the media in echoing and amplifying particular views. Educators are faced with a challenge relating to how they can support learners to develop skills of critical thinking and critical information and media literacy when engaging with information and news sources that present claims of "truth" and "fake news". This is not something that is confined to any particular subject, such as school-based media studies, English, or social studies. Claims about fake news are made in relation to medical developments, scientific evidence, and mathematical modelling. Skills of critical thinking and ability to interrogate sources of information for credibility, perspectives, and political agendas are important learning across the curriculum.

\section{This collection}

I have highlighted issues of curriculum access, social justice, and learning that were presented by global events in 2020 and which I think are likely of interest and important for educators and policy makers in Aotearoa New Zealand and globally in the present and looking forward. Three of the articles in this collection focus on specific curriculum matters that relate to particular Aotearoa New Zealand curriculum policies and teaching initiatives that the 


\section{Editorial}

authors have also identified as important, because they may be problematic or present opportunties for valuable learning for children and young people. While these contributions to curriculum discussions are focused on the Aotearoa New Zealand context, they connect with broader questions of interest to curriculum scholars and teachers-namely, how teachers think about children and assumptions made about young children as learners; how curriculum policies can carry different and potentially confusing or contradictory messages which teachers need to interpret and make sense of in practice; and the nature of learner capabilities and how the development of capabilities supports learners' critical thinking. One article focuses on education in South Korea. It too addresses questions about students' learning, particularly the pedagogical practices that support academic learning within shadow education (private supplementary tutoring).

From the early childhood education context, Beverley Clark and Hilda Hughson offer a commentary on the idea and phrase within Te Wharriki (the Aotearoa New Zealand early childhood curriculum) that children need to "learn how to learn". For them, this phrase is a loose thread in the curriculum. It is problematic for the deficit message it may be seen to carry about children as learners and tension between this message and other messages within the curriculum of children as confident, competent, and powerful learners. They highlight how words matter in curriculum policy, for the meanings that are carried and the potential messages that may be taken.

In a critical policy analysis of the English Language Learning Progressions, Judith Anthony considers the messages carried in this document in the context of a suite of policies that guide teaching and learning for English language learners. The analysis highlights the potential challenges for primary teachers in interpreting and understanding these documents. Also, the different purposes for which the policy is used are highlighted, including as a mechanism to generate funding for support for English language learners, which suggests potential for inequities in access to funding depending on the understanding and familiarity of teachers with the policy and its funding purpose.

Focusing on primary science teaching and learning, Dayle Anderson, Cathy Buntting, Melissa Coton, and co-authors report on a TLRI project where they explored the impact of online citizen science projects on 
science education and the development of science capabilities for primary children. In reporting findings relating to one case study class, they focus on the teacher's decision making and children's learning in relation to a citizen science project on light pollution; in particular, how the teacher supported children's learning in relation to the science capability to critique evidence and the extent to which the children could do this. They highlight the importance of teachers engaging with the intent of the New Zealand curriculum for science and with the science capabilities to understand the potential for children's learning in science.

Researching within the South Korean educational system, Young Chun Kim, Michael McVey and Jung-Hoon Jung investigate how pedagogical practices in shadow education can help students to gain and maintain higher academic achievement. Shadow education is well-established in South Korea but different forms of private supplementary tutoring are pursued in a range of countries, including Aotearoa New Zealand, making an investigation of practices within shadow education relevant to Aotearoa New Zealand and international educators and researchers who are interested in curriculum, teaching, and learning. Highlighted by the research are four features of shadow education practices in South Korea that support academic achievement and student success with examinations.

While the articles focus on different curriculum matters, together they emphasise the importance of teachers engaging thoughtfully with policy, including national curricula and allied policies and guidelines, and pedagogical practice. They highlight the importance of support for teachers to assist them to deeply understand curriculum policy, its intentions and contradictions, for the benefit of learners; also, to understand different pedagogical practices, their theoretical underpinnings and the foundations of these practices within educational systems, and how different practices support different forms of learning and learner achievement.

Jane Abbiss

General Editor 